\title{
Atypical progeroid syndrome (p.E262K LMNA mutation): a rare cause of short stature and osteoporosis
}

\author{
Marina Yukina, Nurana Nuralieva, Ekaterina Sorkina, Ekaterina Troshina, \\ Anatoly Tiulpakov, Zhanna Belaya and Galina Melnichenko
}

Correspondence should be addressed to E Sorkina

Email

sorkina@bk.ru

\section{Summary}

Lamin A/C (LMNA) gene mutations cause a heterogeneous group of progeroid disorders, including Hutchinson-Gilford progeria syndrome, mandibuloacral dysplasia, atypical progeroid syndrome (APS) and generalized lipodystrophyassociated progeroid syndrome (GLPS). All of those syndromes are associated with some progeroid features, lipodystrophy and metabolic complications but vary differently depending on a particular mutation and even patients carrying the same gene variant are known to have clinical heterogeneity. We report a new 30-year-old female patient from Russia with an APS and generalized lipodystrophy (GL) due to the heterozygous de novo LMNA p.E262K mutation and compare her clinical and metabolic features to those of other described patients with APS. Despite many health issues, short stature, skeletal problems, GL and late diagnosis of APS, our patient seems to be relatively metabolically healthy for her age when compared to previously described patients with APS.

\section{Learning points:}

- Atypical progeroid syndromes (APS) are rare and heterogenic with different age of onset and degree of metabolic disorders, which makes this diagnosis very challenging for clinicians and may be missed until the adulthood.

- The clinical picture of the APS depends on a particular mutation in the LMNA gene, but may vary even between the patients with the same mutation.

- The APS due to a heterozygous LMNA p.E262K mutation, which we report in this patient, seems to have association with the generalized lipodystrophy, short stature and osteoporosis, but otherwise, it seems to cause relatively mild metabolic complications by the age of 30 .

- The patients with APS and lipodystrophy syndromes require a personalized and multidisciplinary approach, and so they should be referred to highly specialized reference-centres for diagnostics and treatment as early as possible.

- Because of the high heterogeneity of such a rare disease as APS, every patient's description is noteworthy for a better understanding of this challenging syndrome, including the analysis of genotype-phenotype correlations.

\section{Background}

Atypical progeroid syndromes (APS) are extremely rare and heterogenic, caused by de novo heterozygous LMNA mutations, and usually associated with either partial or generalized lipodystrophy (GL) $(1,2,3)$. APS is a group of systemic disorders with different age of onset and degree of metabolic disorders, which makes this diagnosis very challenging for clinicians.

APS patients have some overlapping clinical signs with Hutchinson-Gilford progeria syndrome (HGPS) and mandibuloacral dysplasia (MAD), variable progeroid 
features such as short stature, beaked nose, partial alopecia, high-pitched voice, and skin atrophy over the hands and feet, as well as having diabetes, GL, skin pigmentation, and mandibular hypoplasia (1). The onset of clinical manifestations in APS patients is later than in HGPS and MAD patients, and they were reported to live longer than HGPS patients, who have a median age of death of about 13 years $(4,5,6,7)$. In this article we have reported an unusual clinical presentation of the APS with GL, short stature and osteoporosis with relatively mild metabolic complications in a 30-year-old patient.

\section{Case presentation}

A 30-year-old female patient of Tatarian origin from the Republic of Dagestan, Russia, was referred to the Endocrinology Research Centre, Moscow, with low weight, no weight gain, loss of appetite, weakness, unformed stool (two times a day), hair loss (head, brows), episodes of vision impairment for 2 or 3 days with spontaneous remission, episodes of tachycardia and heartache, repeated aches in the lower thoracic spine.

Her height at birth was $48 \mathrm{~cm}$, weight at birth was 3200 g, early physical development was normal until the age of 9, except for the teeth dislocation, which was corrected with orthodontic braces. At the age of 9 years, the patient was diagnosed with the retardation of growth and low weight. At the age of 13 years, the bone age corresponded to the age of 10 , at the age of 17 - to the age of 18 years, bone growth plates were not completely closed, GH level was $0.46 \mathrm{ng} / \mathrm{mL}$. At the age of 19 years, despite the closure of the bone growth plates, bone age 20-21, normal GH rates, the patient started GH injections without prescription, which she injected $1.4 \mathrm{mg}$ a day for 6 months. After that, she noticed acromegalic features (nose and ears enlargement, hands and feet size increase) and stopped the GH therapy. At the age of 24 years, rhinoplasty was performed. Since the age of 26 the patient has noticed a weight loss $(3 \mathrm{~kg})$ due to a loss of appetite and an early satiety after a small portion of food. High-fat food has caused nausea and vomiting. At the age of 29 years, her GH was $20.6 \mathrm{ng} / \mathrm{mL}$ (normal range $0-5$ ) and IGF-1 level was normal.

\section{Family history}

Born in a non-consanguineous marriage. From the mother's side: uncle had a body mass deficit, grandfather had camptodactylia. There was no medical information about the father and his relatives. The mother's height -
$160 \mathrm{~cm}$, the father's height $-173 \mathrm{~cm}$, the sister's height $-160 \mathrm{~cm}$.

\section{Physical examination}

The patient had an asthenic constitution (Fig. 1), her height was $140 \mathrm{~cm}$, weight: $22.6 \mathrm{~kg}$, BMI: $11.5 \mathrm{~kg} / \mathrm{m}^{2}$, which means a severe weight deficit. Standard deviation score (SDS) of the weight: 4.74 and of the height: 3.95.

The Patient's head was relatively big to her trunk with the following characteristics: viscerocranium prevalent over neurocranium (Fig. 2), doll's face (mandibular hypoplasia) (Fig. 3), distoclusion (Fig. 4), bilateral exophthalmos (Fig. 5), Graefe's sign, no eyebrows (permanent makeup), big external ears.

The patient had a camptodactylia (deformity in flexion of the proximal phalangeal joint of the 5 th finger on both

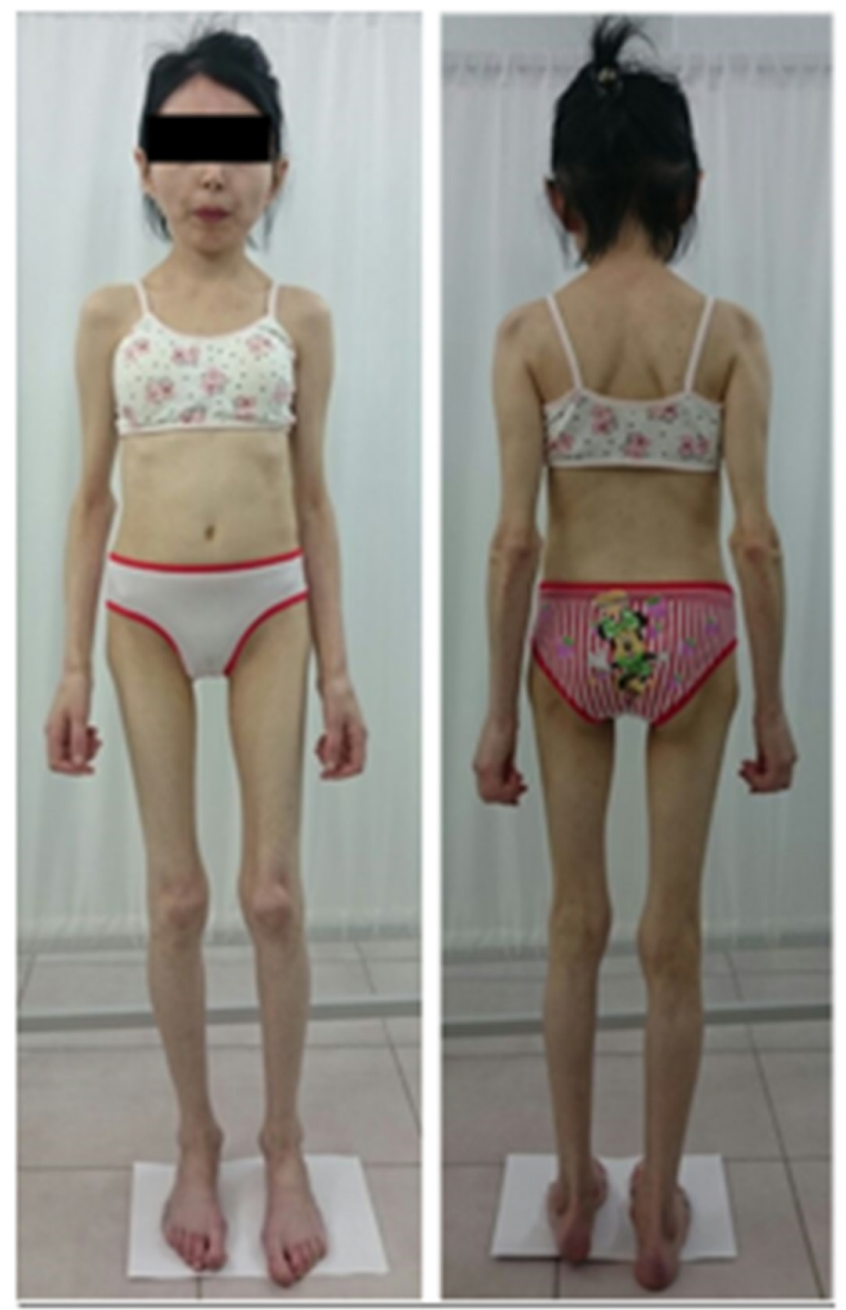

Figure 1

Asthenic complexion, body mass deficiency. 


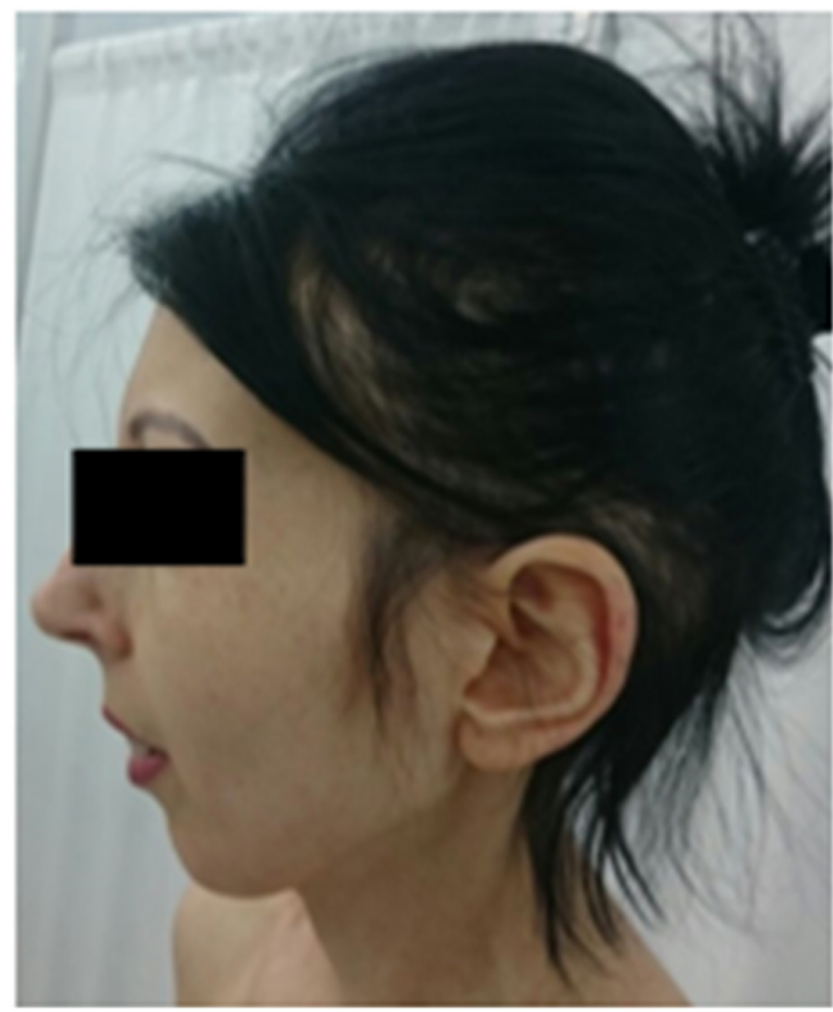

\section{Figure 2}

The prevalence of viscerocranium over neurocranium, mandibular hypoplasia, big external ears.

upper limbs), moderate hypertrichosis on her back (Fig. 6), multiple telangiectasias on her chest and the upper part of her back (Fig. 7), hypomastia, livedo on the lower limbs. The patient had a high-pitched voice, like a child.

\section{Investigation}

Skin fold measurements and impedancemetry showed a significant decrease in subcutaneous fat tissue. The skin fold measurements were as following: subscapular skin fold, $8 \mathrm{~mm}$; triceps skin fold, $10 \mathrm{~mm}$; anterior surface of the abdomen skin fold, $14 \mathrm{~mm}$; anterior surface of the thigh skin fold, $14 \mathrm{~mm}$. Impedancemetry showed $0.7 \mathrm{~kg}$ (3\%) of body fat.

The laboratory data is presented in Tables 1 and 2. There was a constant thrombocytosis and absolute lymphocytosis with mild anemia and normal iron, ferritin, folic acid and B12 vitamin levels. The first stage of the differential diagnosis was to exclude adrenal and thyroid pathology.

\section{Growth hormone metabolism}

Initially there was a significant increase of GH level - 30.9 $\mathrm{ng} / \mathrm{mL}$ (0.06-6.9) with normal IGF-1 level - $236.5 \mathrm{ng} / \mathrm{mL}$

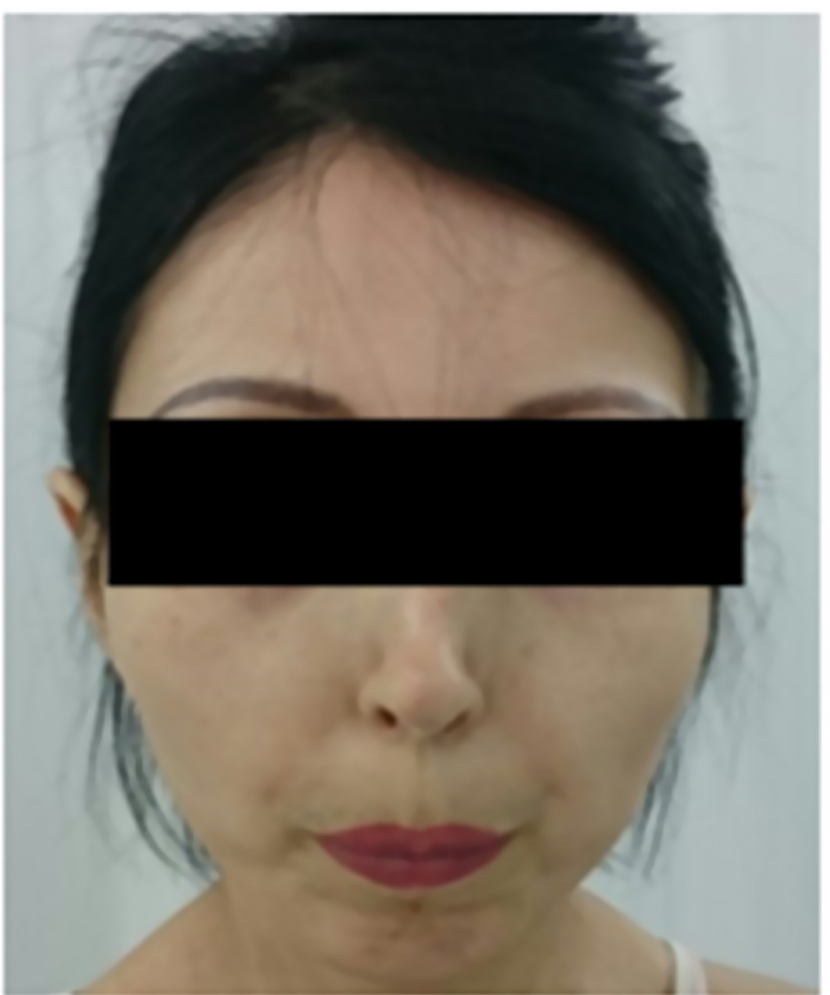

Figure 3

Mandibular hypoplasia.

(60-280). However, during repeated tests there was an increase in IGF-1 level up to a maximal level of $335.8 \mathrm{ng} / \mathrm{mL}$, GH level at a lower edge of norm. Acromegaly was excluded in OGTT (Table 1).

\section{Cardiovascular system}

Cardiac auscultation: systolic murmur in all auscultatory sites. The patient's blood pressure was 140/90 mm Hg, heart rate 100 b.p.m. ECG showed distinctive sinus

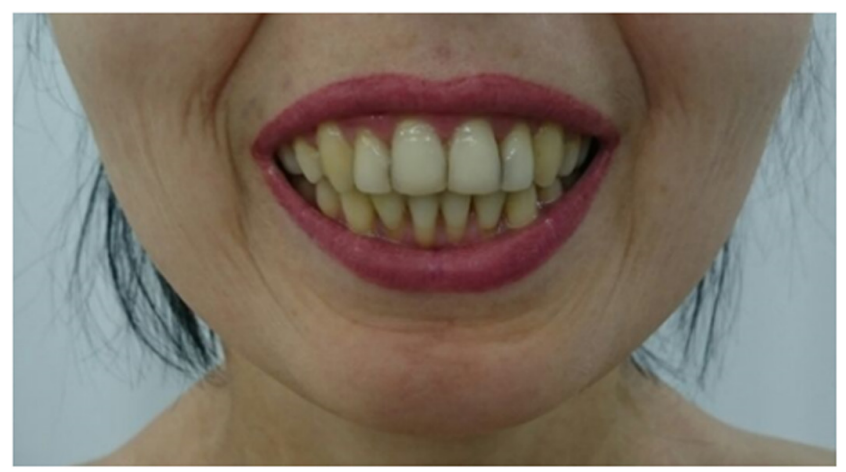

Figure 4

Distoclusion. 


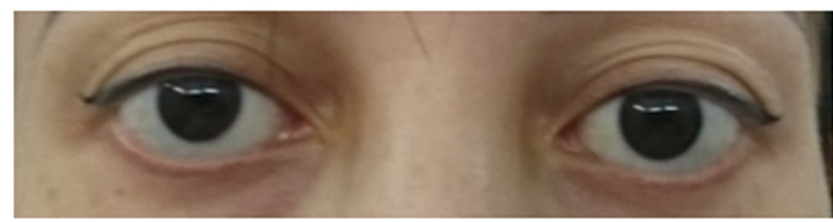

Figure 5

Exophthalmos.

tachycardia, echocardiography showed degenerativecalcific changes of the aortic valve (mild aortic stenosis and insufficiency) and mitral valve, but cardiac chambers size, local kinetics and left ventricular ejection fraction were normal. She had dyslipidemia with elevated total cholesterol and LDL, but with normal triglycerides and HDL levels.

\section{Bone pathology/calcium-Vit D metabolism}

The laboratory tests showed hypercalcemia, hyperphosphatemia, normal PTH and alkaline phosphatase levels and hypocalciuria (Tables 1 and 2). There were no signs of chronic kidney disease. Vitamin D deficiency was diagnosed. The densitometry showed osteopenia of the lumbar spine (T-score L1L4: -2.5 ), osteoporosis of the proximal femur (T-score

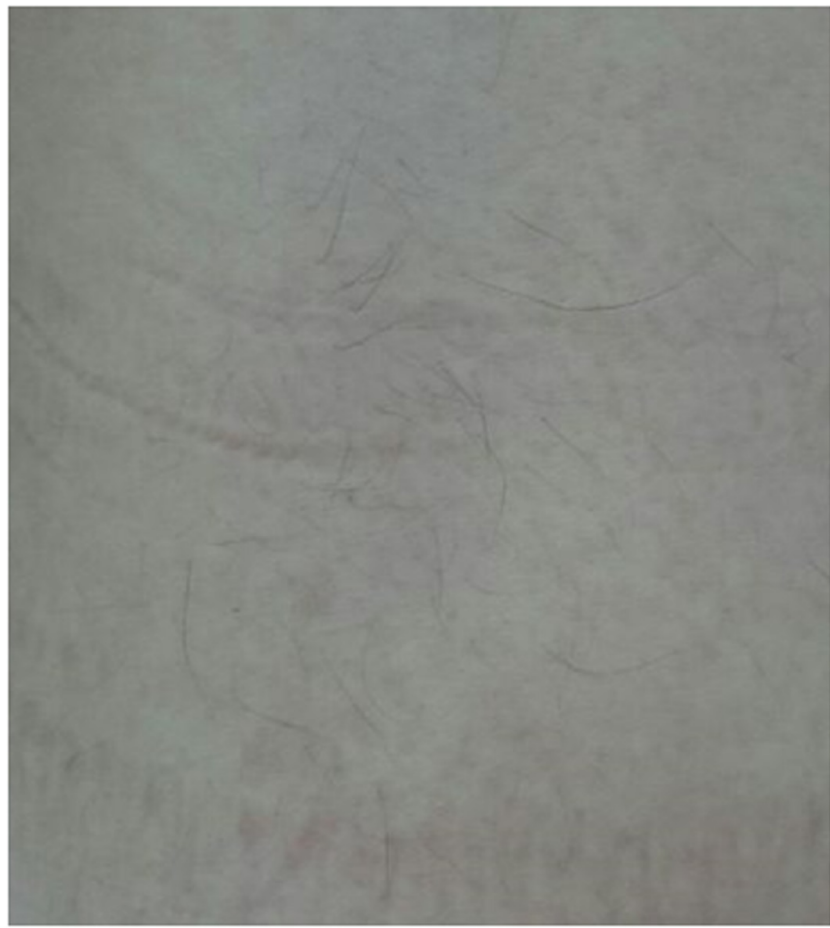

Figure 6

Moderate hypertrichosis on the patient's back.

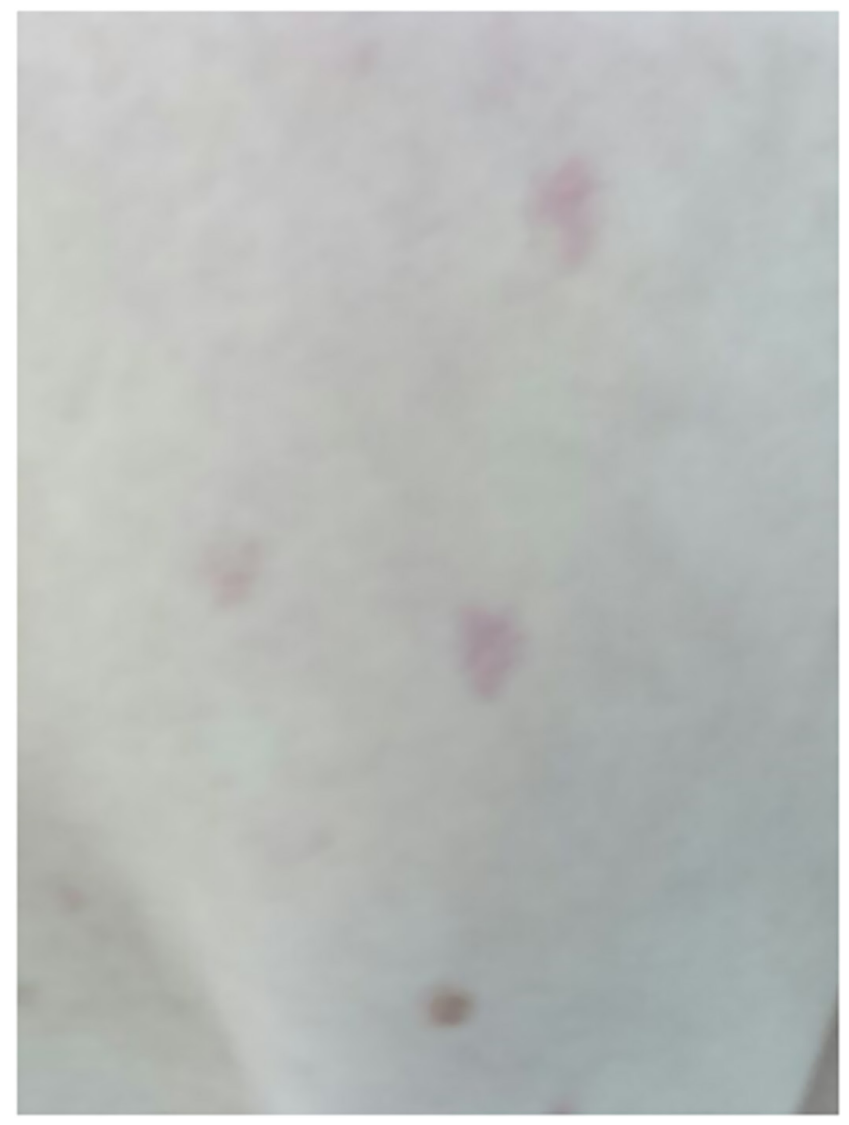

Figure 7

Multiple telangiectasias of the upper part of the back.

neck: -3.4). There was calcification of soft tissues of the interosseous zone of the right forearm on the X-ray of the hands (Fig. 8), the bone age of an adult. The X-ray picture of the knee joints in 2 anatomical projections (Fig. 9) revealed a combination of osteoporosis and osteodystrophy. Laboratory tests showed an insignificant increase of the rheumatoid factor and normal levels of creatinphosphokinase, antistreptolysin $\mathrm{O}$ and C-reactive protein.

Because of the pain in the lower thoracic spine, an MRI was performed but no spinal pathology was found.

\section{Digestive system}

There were no signs of coeliac disease or intestinal helminthic invasion. The coprogram was normal. The esophagogastroduodenoscopy showed cicatricial deformity of duodenal bulb. An abdominal ultrasound showed moderate hepatomegaly, chronic pancreatitis and cholecystitis. 
Table 1 Laboratory data (blood. Age 30 years).

\section{Variables}

Complete blood cell count

Thrombocytes $\times 10^{9}$ cells $/ L$

Lymphocytes $\times 10^{9}$ cells $/ L$

Hemoglobin, g/L

Biochemistry

Glucose(fasting), $\mathrm{mmol} / \mathrm{L}$

Glucose (2 h after $82.5 \mathrm{~g}$ of $\mathrm{GMH}$ load), $\mathrm{mmol} / \mathrm{L}$

Total cholesterol, $\mathrm{mmol} / \mathrm{L}$

$\mathrm{LDL}, \mathrm{mmol} / \mathrm{L}$

$\mathrm{HDL}, \mathrm{mmol} / \mathrm{L}$

Triglycerides, $\mathrm{mmol} / \mathrm{L}$

Calcium, $\mathrm{mmol} / \mathrm{L}$

Albumin, g/L

Calcium, corrected for ALB level, $\mathrm{mmol} / \mathrm{L}$

Phosphates, $\mathrm{mmol} / \mathrm{L}$

Phosphates, $\mathrm{mmol} / \mathrm{L}$ (repeated)

Creatinine, $\mu \mathrm{mol} / \mathrm{L}$

Urea, $\mathrm{mmol} / \mathrm{L}$

GFR (EPI), $\mathrm{mL} / \mathrm{min}$

Iron, $\mu \mathrm{mol} / \mathrm{L}$

Ferritin, $\mathrm{ng} / \mathrm{mL}$

Vitamin B12, pmol/L

Folic acid, ng/mL

Alkaline phosphatase, U/L

Creatinphosphokinase, U/L

Hormone panel

$\mathrm{GH}, \mathrm{ng} / \mathrm{mL}$

$\mathrm{GH}, \mathrm{ng} / \mathrm{mL}$ (repeated)

$\mathrm{GH}(\mathrm{ng} / \mathrm{mL})$ after $82.5 \mathrm{~g}$ of $\mathrm{GMH}$ load

$30 \mathrm{~min}$

$60 \mathrm{~min}$

$90 \mathrm{~min}$

$120 \mathrm{~min}$

IGF-1, ng/mL

IGF-1, ng/mL (repeated)

Immunoreactive insulin, $\mathrm{mcU} / \mathrm{mL}$

HOMA-IR

Leptin, $\mathrm{ng} / \mathrm{mL}$

PTH, pg/mL

Vitamin $\mathrm{D}, \mathrm{ng} / \mathrm{mL}$

$\mathrm{LH}, \mathrm{U} / \mathrm{L}$

$\mathrm{FSH}, \mathrm{U} / \mathrm{L}$

Estradiol, pmol/L

Prolactin, $\mathrm{mU} / \mathrm{L}$

Testosterone, $\mathrm{nmol} / \mathrm{L}$

17-OH-progesterone, $\mathrm{nmol} / \mathrm{L}$

ACTH, pg/mL

Cortisol, $\mathrm{nmol} / \mathrm{L}$

DHEAS, $\mu \mathrm{mol} / \mathrm{L}$

TSH, $\mathrm{mUI} / \mathrm{L}$

Thyroxine, pmol/L

Immunologic tests

Rheumatoid factor, $1 \mathrm{U} / \mathrm{mL}$

Antistreptolysin $\mathrm{O}, \mathrm{IU} / \mathrm{mL}$

C-reactive protein, $\mathrm{mg} / \mathrm{L}$

\begin{tabular}{|c|c|}
\hline Values & Normal range \\
\hline 466 & $152-372$ \\
\hline 4.48 & $1.1-3.4$ \\
\hline 110 & $112-153$ \\
\hline 4.4 & $3.1-6.1$ \\
\hline 5.59 & $<7.8$ \\
\hline 5.27 & $3.3-5.2$ \\
\hline 3.3 & $1.1-3.0$ \\
\hline 1.65 & $1.15-2.6$ \\
\hline 0.8 & $0.1-1.7$ \\
\hline 2.73 & $2.1-2.55$ \\
\hline 47 & $35-50$ \\
\hline 2.59 & $2.1-2.55$ \\
\hline 1.62 & $0.74-1.52$ \\
\hline 1.5 & $0.74-1.52$ \\
\hline 46.7 & $50-98$ \\
\hline 3.5 & $2.5-6.7$ \\
\hline 71 & $>90$ \\
\hline 13.5 & $9-30.4$ \\
\hline 52.5 & $15-160$ \\
\hline 152 & $50-165$ \\
\hline 12.5 & $3.1-17.5$ \\
\hline 96 & $50-150$ \\
\hline 137 & $29-168$ \\
\hline & $0.06-6.9$ \\
\hline \multirow{2}{*}{0.279} & $0.06-6.9$ \\
\hline & Nadir after 82 \\
\hline
\end{tabular}

9.0

3.5

2.6

0.5

236.5

335.8

12.25

2.4

4.6

26.13

17.6

4.7

5.4

159.6

481

0.4

5.8

32.22

513.7

1.85

1.719

11.8

$60-280$

$60-280$

2.3-26.4

$<2.77$

3.7-11.1

$15-65$

30-100

2.6-12

1.9-11.7

97-592

90-540

$0.1-2.7$

$0.82-9.6$

7-66

123-626

2.68-9.23

0.25-3.5

9-20

$38.2 \quad 0-30$

$<50 \quad 0-200$

$0.6 \quad 0.1-5$

ALB, albumin; GMH, glucose monohydrate. 
Table 2 Laboratory data (urine; age 30 years).

\begin{tabular}{|c|c|c|}
\hline Variables & Values & $\begin{array}{c}\text { Normal } \\
\text { range }\end{array}$ \\
\hline Calcium, mmol/24 h & 2.388 & $2.5-8.0$ \\
\hline Calcium-creatinine ratio & 1.06 & - \\
\hline 24-h excretion of metanephrine, $\mu \mathrm{g} / 24 \mathrm{~h}$ & 134.8 & $25-312$ \\
\hline 24-h excretion of normetanephrine, $\mu \mathrm{g} / 24 \mathrm{~h}$ & 144 & $35-445$ \\
\hline
\end{tabular}

\section{Reproductive system}

The patient had a regular menstrual cycle, menarche at the age of 16 years, virgo. There was a hypoplasia of labia majora and minora, no pathology at pelvic ultrasound scan. Breast ultrasound scan showed that the breasts are represented predominantly by fat tissue and glandular tissue is visualized only in a small central locus with a fibroadenoma of the right breast.

\section{Nervous system}

The patient is of normal intelligence, she graduated from school and college, she has been working as a laboratory assistant. Neurological examination revealed decreased temperature sensitivity. There were no signs of real exophthalmos and cataracts. Brain MRI showed multiple focal brain ischemic-hypoxic lesions of perinatal genesis

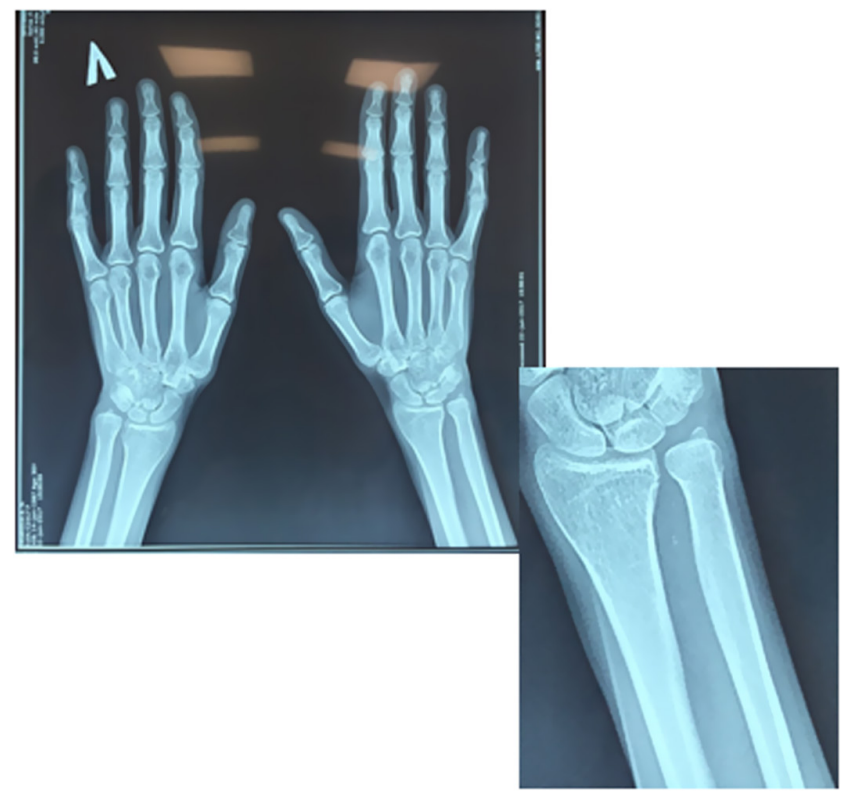

\section{Figure 8}

Early calcinosis of the walls of the soft tissues in the interosseous zone of the right forearm (indicated with a red arrow); coaptation of the diaphyses of the 4th and 5th metacarpal bones (indicated with violet arrows); valgus deviation of the phalangeal joints of the 5th fingers with the formation of flexion contractures in the proximal phalangeal joints of the 5th fingers (indicated with green arrows). combined with acquired leukoencephalopathy and central pontine and extrapontine myelinolysis (Fig. 10). Besides, residual structures of Rathke's pouch were found.

The patient was consulted by a psychiatrist, anorexia nervosa was excluded but a depressive disorder of medium severity was diagnosed.

\section{Molecular genetic results}

Based on clinical signs of a progeroid syndrome with GL in a 30-year-old woman (short stature, dyscrania, mandibular hypoplasia, teeth pathology, doll's face, high-pitched voice, hair loss, false exophthalmos) and the diagnostic tests' results (atherogenic dyslipidemia, cardiac valvular calcinosis, mineral bone density decrease, fingers' deformity, hepatomegaly, duodenal ulcer), APS was suspected. Due to the variety of clinical features of different types of lipodystrophy syndromes and progeroid syndromes sequencing of 18 lipodystrophy candidate genes (AGPAT2, BSCL2, CAV1, CAVIN1, PSMB8, LMNA, PPARG, PLIN1, AKT2, CIDEC, LIPE, LMNB2, PIK3CA, PPP1R3A, POLD1, WRN, ZMPSTE24, BANF1) using a custom Ion Ampliseq panel and Personal Genome Machine (ThermoFisher Scientific, Waltham, MA, USA) semiconductor sequencer (Ion Torrent) was performed. A heterozygous variant c.784G $>$ A: p.E262K was detected in the LMNA gene, confirming the diagnosis of an APS. This mutation was previously reported in an Italian 25-yearold patient with a progeroid syndrome, born from nonconsanguineous healthy parents (8). Jpred-4 program has also defined this variant as highly pathogenic with a 95-98\% chance of penetration.

\section{Treatment}

The patient consumed $1800-1900 \mathrm{kcal}$ a day, with an extra consumption of saturated fats - up to $110 \mathrm{~g}$ a day. She was recommended to follow a well-balanced diet (50-60\% carbohydrate, $20-30 \%$ fat, $20 \%$ protein), with primarily cis-mono-unsaturated fats and long-chain omega-3 fatty acids. Enzymes (Pancreatin 10000 U 1 caps.), cholagogues and spasmolytics were prescribed for improved digestion. Antidepressants (clomipramine $25 \mathrm{mg} 1 / 2$ tabl. in the morning and afternoon during 1 week, then 1 tabl. in the morning and afternoon; mirtazapine $30 \mathrm{mg} 1 / 2-1$ tabl. at night) and an anxiolytic (bromdihydrochlorphenylbenzodiazepine $0.5 \mathrm{mg} 1 / 4 \mathrm{tabl}$. depending on the patient's condition) were prescribed to treat a depressive disorder. 


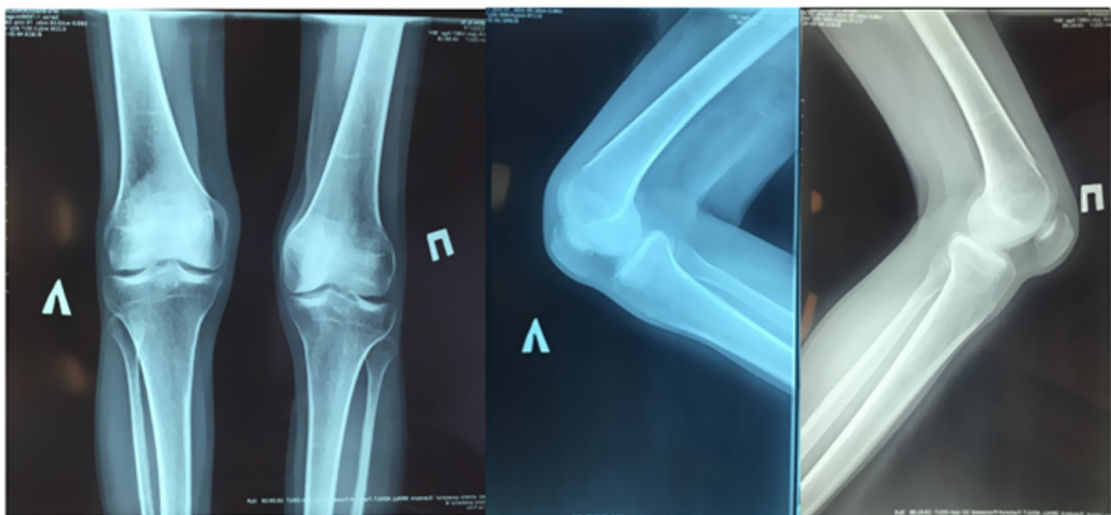

\section{Figure 9}

The X-ray picture of the knee joints in two anatomical projections. There was an extreme cross-striation of femoral and tibial diaphysis, and of fibular marginal layers. Orthopedic valgoid semiluxation was also diagnosed in the right knee joint by the X-ray. The patient also had a flat-foot and supportive overexertion of the right foot. There were early signs of arthrosis and secondary distention of the right tibiofibular space.
Taking into account cardiac valvular calcinosis and dyslipidemia hypolipidemic (rosuvastatin $10 \mathrm{mg}$ at night) and antiplatelet (acetylsalicylic acid $150 \mathrm{mg}$ at night) therapy was initiated. A beta-blocker (bisoprolol $2.5 \mathrm{mg}$ in the morning) was prescribed to treat tachycardia. As the first step to treat osteopenia and compensate vitamin D deficiency, cholecalciferol (50 drops twice a week during 8 weeks) was prescribed and it was recommended that the patient start bisphosphonates therapy after achieving vitamin D normal levels. Orthopedic shoes and therapeutic exercises were prescribed.

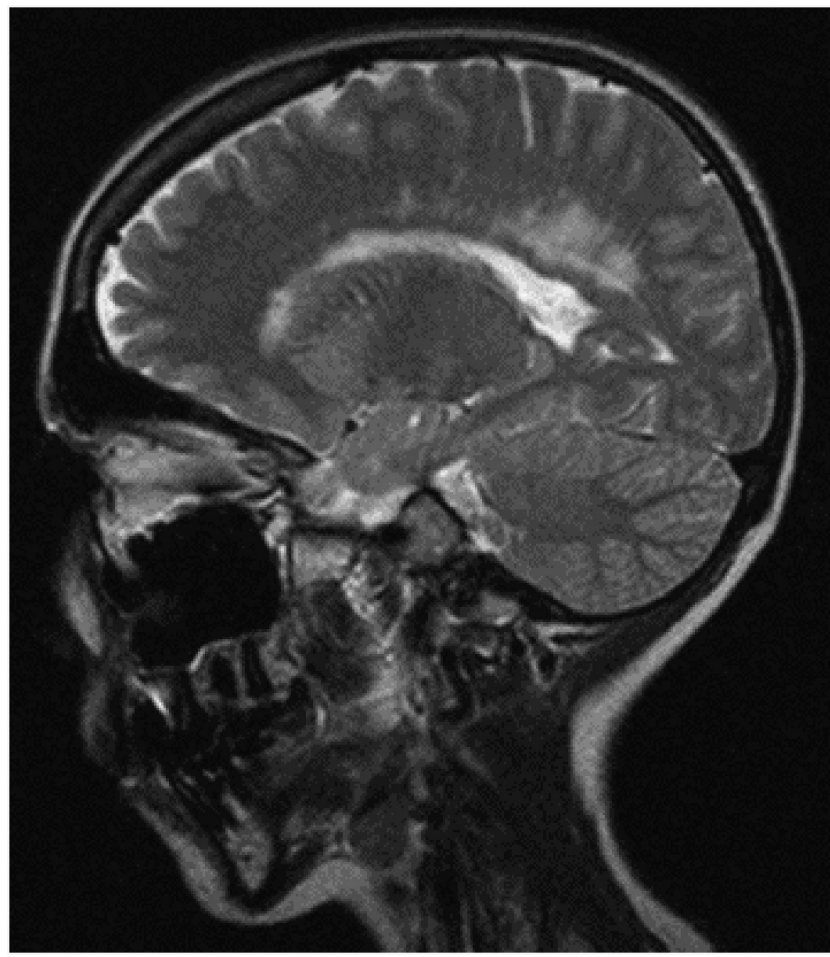

Figure 10

The MRI brain scan (T2-weighted MRI, sagittal slice).

\section{Outcome and follow-up}

The patient is stable, following all the prescriptions. After 2 months, when normal serum vitamin $\mathrm{D}$ levels were reached, Alendronic acid was prescribed, $70 \mathrm{mg}$ per week.

\section{Discussion}

Like many patients with lipodystrophy syndromes and APS, our patient experienced a late diagnosis of this congenital disorder. The diagnostic of APS in this case was complicated by previous growth hormone selfadministrated therapy followed by a rhinoplasty.

Genetic and phenotypic heterogeneity is well documented in patients with APS, every patient being unique. Unfortunately, there is no detailed information about the only Italian patient with a progeroid syndrome carrying the same mutation as our patient (8). The largest group of APS patients was analyzed by Hussain et al. (2), therefore we are referring to this data to compare the

Table 3 Comparison of clinical features of patient 1 with patients with APS and GLPS described by Hussain et al. (2).

Type of lipodystrophy

Generalized, $\%$

Partial, \%

Unspecified, \%

None, \%

Diabetes mellitus, \%

Hypertension, \%

Hypertriglyceridemia,\%

Joint contractures, \%

Cardiomyopathy, \%

Valvular disease, $\%$

Scoliosis, \%

Mottled skin, \%

Hepatomegaly, \%

Acanthosis nigricans, \%

Small atrophic breasts,\%

\begin{tabular}{c}
\hline Patient 1 \\
\hline+ \\
\\
+ \\
+ \\
+ \\
+ \\
- \\
+ \\
+ \\
- \\
+ \\
- \\
+
\end{tabular}

APS

28

32

24

16

36

$$
50
$$

46.2

62

59

63

29

89

50

$\begin{array}{r}\hline \text { GLPS } \\ \hline 84 \\ 8 \\ 8 \\ 0 \\ 85 \\ 50 \\ 100 \\ 89 \\ 70 \\ 80 \\ 38 \\ 100 \\ 100 \\ 40 \\ 100 \\ \hline\end{array}$


Table 4 Comparison of metabolic parameters patient 1 with patients with APS and GLPS described by Hussain et al. (2). Medians and ranges are presented for continuous variables.

\begin{tabular}{|c|c|c|c|}
\hline Parameter & Patient 1 & APS & GLPS \\
\hline $\begin{array}{l}\text { Age reported, } \\
\text { years }\end{array}$ & 30 & $23.0(7-53)$ & $14(8-55)$ \\
\hline $\mathrm{BMI}, \mathrm{kg} / \mathrm{m}^{2}$ & 11.5 & $15.4(10.1-19.6)$ & $14.6(11.4-25.1)$ \\
\hline $\begin{array}{l}\text { Fasting TG, } \\
\mathrm{mg} / \mathrm{dL}\end{array}$ & 70.8 & $121(34-3000)$ & $776(238-10623)$ \\
\hline $\mathrm{ALT}, \mathrm{mU} / \mathrm{L}$ & 15 & 36.5 (13-287) & $83.5(11-216)$ \\
\hline AST, mU/L & 19 & $44.5(16-134)$ & $51(20-120)$ \\
\hline $\begin{array}{l}\mathrm{HDL} \\
\text { cholesterol, } \\
\mathrm{mg} / \mathrm{dL}\end{array}$ & 63.8 & $40.5(14.6-50.0)$ & $21.0(6-42)$ \\
\hline Leptin, ng/mL & 4,6 & $3.0(0.8-12.6)$ & $0.3(0-4.0)$ \\
\hline $\begin{array}{l}\text { Fasting glucose, } \\
\mathrm{mg} / \mathrm{dL}\end{array}$ & 79.28 & $93(84-277)$ & $125(74-283)$ \\
\hline $\begin{array}{l}\text { Fasting insulin, } \\
\mu \mathrm{U} / \mathrm{mL}\end{array}$ & 12.25 & $14.7(1.9-85.0)$ & $55.2(8.7-290)$ \\
\hline $\begin{array}{l}\text { Total body fat, } \\
\text { b }(\%)^{1}\end{array}$ & 3 & $17.2(6.5-27.0)$ & $8.5(0.04-25.0)$ \\
\hline
\end{tabular}

described clinical features with the manifestations in our patient (Tables 3 and 4).

It was suggested by Hussain et al. to distinguish a novel generalized lipodystrophy-associated progeroid syndrome (GLPS) due to a recurrent heterozygous LMNA p.T10I mutation from the rest of the APS, as GLPS is characterized by more severe metabolic complications of lipodystrophy. These patients were reported to have hypertriglyceridemia, diabetes, hepatomegaly, and acanthosis nigricans early in life, with higher levels of serum triglycerides and insulin, as well as lower levels of serum leptin and HDL cholesterol than others with APS. Only $28 \%$ of other APS patients were reported to have GL, but mottled skin, small atrophic breasts, joint contractures, valvular disease, cardiomyopathy, arterial hypertension, hepatomegaly and hypertriglyceridemia were common in this group. Our patient had only a mild hypertension and hypertriglyceridemia with relatively high HDL levels. She had multiple skeletal pathologies including joint contractures and scoliosis, but only mild cardiac pathology (valvular calcinosis) with no signs of cardiomyopathy. The patient had no mottled skin, just multiple telangiectasias of the upper part of the back, no acanthosis nigricans and no signs of insulin resistance or diabetes. Her leptin level was normal and higher than average leptin level in GLPS group despite the minimal amount of body fat (3\% or $0.7 \mathrm{~kg}$ at impedancemetry). Unfortunately, a DXA scan was not performed on this patient to more accurately assess the distribution of the body fat. Most APS and all GLPS female patients were described to have small atrophic breasts, the ultrasound picture of our patient's breast tissue confirms the presence of these features.

Despite many health issues, short stature, skeletal problems, GL and a late diagnosis of APS, our patient seems to be relatively metabolically healthy for her age when compared to the previously described patients. Because of the high heterogeneity of such a rare disease as APS, every patient's description is noteworthy for a better understanding of this challenging syndrome.

\section{Patient's perspective}

The patient seemed predominantly worried about her physical appearance (short stature, general lack of fat) and followed the prescriptions accurately, except Alendronic acid, which she discontinued after a month because of the 'pain in the bones'.

Declaration of interest

The authors declarethat there is no conflict of interest that could be perceived as prejudicing the impartiality of the research reported.

\section{Funding}

This work was supported by the state assignment 'The development of personalized approaches to the diagnosis and treatment of patients with osteoporosis due to endocrinopathies based on the study of molecular genetic predictors, innovative diagnostic methods and pathogenesis research' (grant number: AAAA-A20-120011690202-4).

\section{Patient consent}

Written informed consent for publication of her clinical details and clinical images in this journal was obtained from the patient.

\section{Author contribution statement}

$M Y$ is the main author, who originally proposed the article, clinically suspected generalized lipodystrophy and a progeroid syndrome in the patient and took part in writing the manuscript. $\mathrm{N} \mathrm{N}$ made a major contribution to the writing of the manuscript and prepared the figures. $\mathrm{M} \mathrm{Y}$ and $\mathrm{N} \mathrm{N}$ were the attending physicians of the patient, provided and interpreted the data of the examination, laboratory and clinical studies. E S consulted the patient to confirm a lipodystrophy syndrome, performed and interpreted skin folds measurements and impedancemetry, prepared Tables 1, 2, 3 and 4, translated and reviewed the manuscript, making a major contribution to the discussion and the conclusions. A T performed and interpreted the genetic study of the patient. E T, Z B, G M consulted the patient in a hospital, reviewed the manuscript and made substantial recommendations. All authors have read and agreed to the published version of the manuscript.

\section{References}

1 Garg A, Subramanyam L, Agarwal AK, Simha V, Levine B, D'Apice MR, Novelli G \& Crow Y. Atypical progeroid syndrome 
due to heterozygous missense LMNA mutations. Journal of Clinical Endocrinology and Metabolism 200994 4971-4983. (https://doi. org/10.1210/jc.2009-0472)

2 Hussain I, Patni N, Ueda M, Sorkina E, Valerio CM, Cochran E, Brown RJ, Peeden J, Tikhonovich Y, Tiulpakov A, et al. A novel generalized lipodystrophy-associated progeroid syndrome due to recurrent heterozygous LMNA p.T10I mutation. Journal of Clinical Endocrinology and Metabolism 2018103 1005-1014. (https://doi. org/10.1210/jc.2017-02078)

3 Brown RJ, Araujo-Vilar D, Cheung PT, Dunger D, Garg A, Jack M, Mungai L, Oral EA, Patni N, Rother KI, et al. The diagnosis and management of lipodystrophy syndromes: a multi-society practice guideline. Journal of Clinical Endocrinology and Metabolism 2016101 4500-4511. (https://doi.org/10.1210/jc.2016-2466)

4 Simha V, Agarwal AK, Oral EA, Fryns JP \& Garg A. Genetic and phenotypic heterogeneity in patients with mandibuloacral dysplasiaassociated lipodystrophy. Journal of Clinical Endocrinology and Metabolism 200388 2821-2824. (https://doi.org/10.1210/jc.2002021575)
5 Hennekam RC. Hutchinson-Gilford progeria syndrome: review of the phenotype. American Journal of Medical Genetics: Part A 2006140 2603-2624. (https://doi.org/10.1002/ajmg.a.31346)

6 Merideth MA, Gordon LB, Clauss S, Sachdev V, Smith AC, Perry MB, Brewer CC, Zalewski C, Kim HJ, Solomon B, et al. Phenotype and course of Hutchinson-Gilford progeria syndrome. New England Journal of Medicine 2008358 592-604. (https://doi.org/10.1056/ NEJMoa0706898)

7 Simha V \& Garg A. Body fat distribution and metabolic derangements in patients with familial partial lipodystrophy associated with mandibuloacral dysplasia. Journal of Clinical Endocrinology and Metabolism 200287 776-785. (https://doi.org/10.1210/jcem.87.2.8258)

8 EURO-laminopathies. Project title: Nuclear envelop-linked rare human diseases: from molecular pathophysiology towards clinical applications. Contract no. 018690 modified final activity report. 01.02.2006-31.01.2009 coordinated by: Prof. Roland Foisner, Medizinische Universität Wien. (available at: https://cordis.europa. eu/docs/results/18/18690/122487731-6_en.pdf). Accessed on 06 November 2020 .

Received in final form 11 November 2020 Accepted 15 March 2021 